\title{
Surface Electron-Hole Rich Species Active in the Electrocatalytic Water Oxidation
}

\author{
Juan-Jesús Velasco-Vélez,* Emilia A. Carbonio, Cheng-Hao Chuang, Cheng-Jhih Hsu, Jyh-Fu Lee, \\ Rosa Arrigo, Michael Hävecker, Ruizhi Wang, Milivoj Plodinec, Feng Ryan Wang, Alba Centeno, \\ Amaia Zurutuza, Lorenz J. Falling, Rik Valentijn Mom, Stephan Hofmann, Robert Schlögl, \\ Axel Knop-Gericke, and Travis E. Jones*
}

Cite This: J. Am. Chem. Soc. 2021, 143, 12524-12534

Read Online

\section{ACCESS}

Wlll Metrics \& More

Article Recommendations

Supporting Information

ABSTRACT: Iridium and ruthenium and their oxides/hydroxides are the best candidates for the oxygen evolution reaction under harsh acidic conditions owing to the low overpotentials observed for Ru- and Ir-based anodes and the high corrosion resistance of Iroxides. Herein, by means of cutting edge operando surface and bulk sensitive X-ray spectroscopy techniques, specifically designed electrode nanofabrication and $a b$ initio DFT calculations, we were able to reveal the electronic structure of the active $\mathrm{IrO}_{x}$ centers (i.e., oxidation state) during electrocatalytic oxidation of water in the surface and bulk of high-performance Ir-based catalysts. We found the oxygen evolution reaction is controlled by the formation of empty Ir 5d states in the surface ascribed to the formation of formally $\operatorname{Ir}^{\mathrm{V}}$ species leading to the appearance of electron-deficient oxygen species bound to single iridium atoms $\left(\mu_{1}-\mathrm{O}\right.$ and $\left.\mu_{1}-\mathrm{OH}\right)$ that are responsible for water activation and oxidation. Oxygen bound to three iridium centers $\left(\mu_{3}-\mathrm{O}\right)$ remains the dominant species in the bulk but do not participate directly in the electrocatalytic reaction, suggesting bulk oxidation is limited. In addition a high coverage of a $\mu_{1}$-OO (peroxo) species during the OER is excluded. Moreover, we provide the first photoelectron spectroscopic evidence in bulk electrolyte that the higher surface-tobulk ratio in thinner electrodes enhances the material usage involving the precipitation of a significant part of the electrode surface and near-surface active species.

\section{INTRODUCTION}

Water splitting is among the most important electrochemical processes for the storage of renewable energy, as the molecular hydrogen produced at the cathode can be used as a carbon-free energy vector. ${ }^{1-3}$ However, anode corrosion under acidic conditions and anodic polarization shortens material lifetimes leading to increased costs. ${ }^{4-6}$ Among all the materials investigated for the oxygen evolution reaction (OER), iridium and ruthenium oxides/hydroxides have received considerable attention owing to their low overpotentials; however, only iridium and its oxides/hydroxides are known to combine low overpotential and corrosion resistance under harsh acidic conditions. ${ }^{7,8}$ Unfortunately, iridium is also one of the scarcest elements on earth; thus, synthetic strategies for optimizing its usage are required. ${ }^{9}$ To develop such strategies it is important to understand what drives stability and activity in these materials. The presence of a distribution of surface species with a mixed oxidation state between $\mathrm{Ir}^{\mathrm{III}}$ and $\mathrm{Ir}^{\mathrm{VI}}$ are suggested ${ }^{10-12}$ to be critical in the nature of the high activity ${ }^{13}$ shown by this element. We reason that determining the electronic structure characteristics responsible for the peculiar
OER performance of $\mathrm{IrO}_{x}$, as well as quantifying the amount of the material and location of the active species participating in the reaction, is key to optimize its electrochemical performance and usage. Herein, we combine operando X-ray absorption spectroscopy (XAS) with operando X-ray photoelectron spectroscopy (XPS) to provide complementary information on the occupied and unoccupied states. Though XPS gives intrinsically more surface information than XAS, we show how the surface sensitivity of XAS can be enhanced through precise nanofabrication of nanostructure electrodes. By increasing the surface-to-bulk ratio of the electrodes through nanostructuring, the surface information provided by XAS is enhanced, though this does not make XAS a strictly surface-sensitive method. By

Received: February 10, 2021

Published: August 6, 2021 
combining these measurements with $a b$ initio calculations, the nature of the active species and their distribution in the surface and near-surface region during the electrocatalytic oxidation of water was determined. It was found that nanostructuring has a significant influence on the overall XAS whiteline intensity as a consequence of the bulk sensitivity of XAS. The XA spectra contain contributions from the different electrode regions (surface and bulk) including the regions of the electrode that are not in direct contact with the electrolyte or other areas where the contact resistance is significantly different due to charge/mass transport limitations. This limits our ability to use XA spectra of bulky electrodes to develop mechanistic pictures of the OER taking place at the electrode/electrolyte interface. Bulky electrodes can also experience chemical changes within different regions as a consequence of slow kinetic processes such as bulk oxidation, different stoichiometries within the electrode, diffusion, and deficient electrolyte wetting. In order to minimize the impact of these unwanted effects and ascribe the changes observed in the electrode to the variation that the electrode surface undergoes during the reaction conditions, different electrode thicknesses were investigated in a welldefined planar electrode configuration, which avoids the use of inks based on ionomers. These results were validated by their comparison with operando soft X-ray XPS in the presence of a bulk aqueous electrolyte with the same type of electrodes and conditions as operando XAS. The XPS measurements provided key information related to the near-surface oxidation state that were not quantifiable by the XAS measurements alone. To the best of our knowledge, this is the first time that these experiments were performed with operando XAS/XPS consecutively with the same type of samples and under the same aqueous bulk electrolyte.

\section{EXPERIMENTAL SECTION}

Electrode Preparation. Details of all preparations are given in the Supporting Information (SI). Briefly, two types of electrode were produced, a thin-film bulk model and a nanoparticulate surface model. The bulk model electrode $\mathrm{IrO}_{x}$ was directly sputtered on a $\mathrm{Si}_{3} \mathrm{~N}_{4}$ membrane and activated/oxidize electrochemically by potential cycling. The surface model electrode was prepared in three steps: (i) a graphene layer was transferred onto a $100 \mathrm{~nm}$ thick $\mathrm{Si}_{3} \mathrm{~N}_{4}$ holey array membrane with $500 \mathrm{~nm}$ diameter holes for XPS or a $100 \mathrm{~nm}$ thick $\mathrm{Si}_{3} \mathrm{~N}_{4} \mathrm{X}$-ray membrane (without holes) for XAS. For the XPS membrane assembly, this process yields a continuous film of graphene with areas supported by the $\mathrm{Si}_{3} \mathrm{~N}_{4}$ membranes and areas which are free-standing over the holes in the $\mathrm{Si}_{3} \mathrm{~N}_{4}$ holey array membrane, while for the XAS membrane assembly the graphene is fully supported by the $\mathrm{Si}_{3} \mathrm{~N}_{4} \mathrm{X}$-ray membrane. In both cases, the membrane can be used as an electrode in electrochemical applications owing to graphene's good electrically conductivity and the cell's leak tightness. Moreover, because the graphene is semitransparent to photoelectrons and photons, ${ }^{14,15}$ the graphene coated holey $\mathrm{Si}_{3} \mathrm{~N}_{4}$ membrane can be used for operando photoelectron spectroscopy under electrochemical conditions, ${ }^{16,17}$ while the fully supported graphene can be used for total fluorescence yield XAS. In order to increase the stability of the graphene membrane for XPS, and cover possible tears/holes in the graphene, a second layer of graphene was transferred to the electrode assembly. SEM measurements of the graphene on the $\mathrm{Si}_{3} \mathrm{~N}_{4}$ grid are shown in Figure S1A and B. These two layers of transferred graphene are referred throughout the text as a bilayered graphene (BLG) membrane. Raman spectroscopy ${ }^{18-21}$ was used to check the quality of the crystallized BLG in order to determine the graphitic character of the free standing graphene samples as shown in the SI. (ii) In a second step the graphene electrode was decorated with Ir nanoparticles (NPs) by sputter coating. The particles cover around $20 \%$ of the graphene surface, and they range from 2 to $5 \mathrm{~nm}$, with an average diameter of $2.5 \mathrm{~nm}$. (iii) Finally, the Ir NPs were activated/oxidized electrochemically by potential cycling in $\mathrm{N}_{2}$ saturated $100 \mathrm{mM} \mathrm{H}_{2} \mathrm{SO}_{4}$ electrolyte. For the operando XAS experiments, the fully supported graphene electrode assembly was decorated with $2.5 \mathrm{~nm}$ sputtered $\mathrm{Ir}$ NPs. The thin film bulk model electrode was prepared by directly sputtering a $20 \mathrm{~nm}$ Ir thin film onto the $\mathrm{Si}_{3} \mathrm{~N}_{4}$ membrane $(100 \mathrm{~nm}$ thick, without holes).

In Situ Experiments. The spectra were collected in two different synchrotron facilities. The in situ soft X-ray photoelectron spectra were recorded at the ISISS beamline of BESSY II in Berlin using an ambient pressure X-ray photoelectron spectrometer (APXPS). Ir $\mathrm{L}_{3^{-}}$ edge spectra were measured in the hard X-ray regime at the beamline BL17C1 of the National Synchrotron Radiation Research Center (NSRRC) in Hsinchu (Taiwan). More details of these beamlines can be found in the Supporting Information.

The Ir $\mathrm{L}_{3}$ edge spectra were collected using the in situ EC-cell shown in Figure S2A, where the flow of liquid was assured with a peristaltic micro pump. This cell is based on a $100 \mathrm{~nm}$ thick $\mathrm{Si}_{3} \mathrm{~N}_{4}$ membrane which allows the collection of the X-ray absorption total fluorescence yield signal while remaining leak tight. ${ }^{22}$ The XP spectra were collected using a different $\operatorname{cell}^{23,24}$ (see Figure S2B) which is compatible with free-standing graphene membranes. The potential and current collection was done via a potentiostat. More details of these approaches can be found in the Supporting Information.

Note that the electrochemical performance and signal collection, as well as the limits and opportunities that these electrochemical cells offer, were discussed in detail elsewhere. ${ }^{25}$ The transmission properties of the photoelectrons traveling through the lens/analyzer are not influenced by the presence of the $\mathrm{Si}_{3} \mathrm{~N}_{4} / \mathrm{BLG}$ as shown in Figure S.3A. The transmission function of the lens and analyzer is smooth and not suddenly dropping. Thus, the transmission function of the lens/hemispherical analyzer remains unaltered when the membrane is incorporated into the system. Furthermore, it is important to remark that the probed depth depends on the KE of the photoelectrons, which is larger at higher excitation energies. In addition, KEs around $500 \mathrm{eV}$ are affected by an overlap with the $\mathrm{O}$ KLL Auger spectra, which makes Ir $4 \mathrm{f}$ spectrum collection impossible. Otherwise, the cross section of the target element decays at higher excitation energies. Consequently, according to Figure S3B, the best compromise between these two parameters is achieved with a kinetic energy equal to $\sim 600 \mathrm{eV}$. Because of this fact, we set the kinetic energy to $600 \mathrm{eV}$ to perform the XP spectra acquisition.

Calculations. Full details of the simulations can be found in the SI. Briefly, density functional theory calculations were performed at the PBE level using the Quantum ESPRESSO package ${ }^{26}$ using pseudopotentials from the PSLibrary ${ }^{27}$ with a kinetic energy (charge density) cutoff of $60 \mathrm{Ry}(600 \mathrm{Ry})$. The effect of adding a Hubbard $U$ correction was studied using $U=1.2 \mathrm{eV}$, which is consistent with the low value expected for $\mathrm{Ir}^{28}$ For bulk rutile-type $\mathrm{IrO}_{2}$ calculations a $(12 \times 12 \times 12) k$-point mesh was used with Marzari-Vanderbilt cold smearing using a $0.01 \mathrm{Ry}$ smearing parameter, ${ }^{29}$ surface simulations used nearly equivalent $\boldsymbol{k}$-point meshes. XAS spectra were computed with a resolvent-based Bethe-Salpeter Equation (BSE) approach ${ }^{30}$ using the wave functions from Quantum ESPRESSO with the corelevel BSE solver in the OCEAN package. ${ }^{31}$ XPS spectra were computed using a Hopfield perturbation model. ${ }^{32}$

\section{RESULTS AND DISSCUSION}

Two different electrodes with different surface-to-bulk ratios were fabricated and compared, namely a $20 \mathrm{~nm}$ thin film and $2.5 \mathrm{~nm}$ nanoparticles (NPs) sputtered deposited on a graphene current collector electrode. The graphene layer is used as a current collector for the $2.5 \mathrm{~nm}$ Ir NPs, where the electrical conductivity between the different Ir NPs is assured by the graphene layer. These two electrodes were characterized with electron microscopy. Thus, Figure 1A shows a top view scanning electron microscopy (SEM) image of the sputtered thin-film electrode, which consists of interconnected poly- 

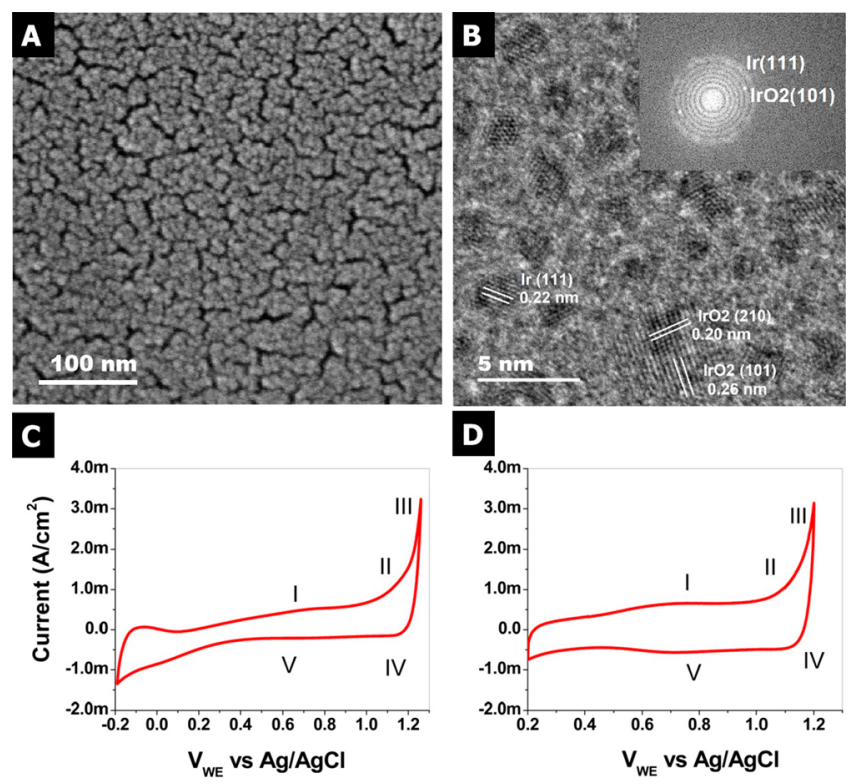

Figure 1. (A) SEM image of the sputtered thin-film $\mathrm{IrO}_{x}$ electrode. (B) TEM characterization of the sputtered $\mathrm{IrO}_{x} \mathrm{NPs}$ onto the freestanding bilayered graphene (BLG) obtained by CVD. CVs of the (C) thin-film IrOx electrode and (D) $\mathrm{IrO}_{x} \mathrm{NPs}$ in $100 \mathrm{mM} \mathrm{H}_{2} \mathrm{SO}_{4}$ with $\mathrm{Pt}$ counter and $\mathrm{Ag} / \mathrm{AgCl}$ reference electrodes, respectively.

crystalline islands with a thickness of $20 \mathrm{~nm}$. According to the SEM image in Figure 1A, we estimate a surface area of about 1.5-2.0 qualitative coverage factor (CF) for the thin film and about $1 / 3 \mathrm{CF}$ for the nanoparticles (with respect to a completely flat surface used as a reference with surface area equal to $1 \mathrm{CF}$ ). In contrast, Figure $1 \mathrm{~B}$ shows the TEM image of the sputtered $2.5 \mathrm{~nm} \mathrm{IrO}_{x}$ NPs supported on a conductive bilayered graphene (BLG) current collector electrode. Owing to the structural differences, the thin film can be considered a bulk model, whereas the high surface-to-bulk ratio of the 2.5 $\mathrm{nm}$ Ir NPs is then a surface model. Note that the freshly sputtered electrodes are metallic. It is well-known that the anodic oxidation of metallic iridium is reported to result in better performing catalysts than thermal activation, due to the existence of highly hydrated species forming an oxyhydroxide upon electro-oxidation. ${ }^{33}$ Hence, in order to increase the electrocatalytic performance and ensure the electrode stoichiometry, the sputtered electrodes were oxidized/ activated prior to their use during the electrocatalytic oxidation of water to dioxygen (established in this experiments at $-1.6 \mathrm{~V}$ vs $\mathrm{Ag} / \mathrm{AgCl}$ ) by several potential scans between open circuit voltage $(\mathrm{OCV})$ and $1.2 \mathrm{~V}$ at $20 \mathrm{mV} / \mathrm{s}$ scanning rate in a 50 $\mathrm{mM} \mathrm{H}_{2} \mathrm{SO}_{4}$ electrolyte (potentials are not $i R$ corrected). The anodic oxidation results in the development of an increasingly larger anodic peak in the cyclic voltammogram $(\mathrm{CV})$, where the peak height increased with the number of cycles. ${ }^{34}$ The condition of maximum peak height corresponds to the highest electrode activity for thin films and NPs. ${ }^{35}$ Thus, the CV treatment oxidizes Ir metal into the more active $\mathrm{IrO}_{x}$. After the anodic oxidation, the samples were characterized with the electron microscopy. Thus, the TEM (Figure 1B) images of the sputtered iridium particles on the free-standing bilayer graphene show that they are homogeneously distributed after activation; the estimated coverage factor is around $20 \%$ of the surface, and the average particle size is $\sim 2.5 \mathrm{~nm}$. Contact of the $\mathrm{IrO}_{x}$ NPs onto graphene is assured by a chemical bond between the surface Ir atoms and the oxygen species present at the edges and vacancies of graphene. ${ }^{36}$ The fast Fourier transform (FFT) proves the existence of reduced metallic iridium NPs (such beam induced reduction is common in nonstoichiometric oxides) and one additional ring ascribed to stoichiometric $\mathrm{IrO}_{2}$.

Furthermore, the electrochemical performance of the $\mathrm{IrO}_{x}$ thin-film and $\mathrm{IrO}_{x} \mathrm{NP}$ electrodes are compared in Figure 1C and $1 \mathrm{D}$. The $\mathrm{CVs}$ were acquired at room temperature $\left(25^{\circ} \mathrm{C}\right)$, in deaerated $100 \mathrm{mM} \mathrm{H}_{2} \mathrm{SO}_{4}$ with $\mathrm{N}_{2}$ continually bubbled in the electrolyte at a scan rate of $20 \mathrm{mV} / \mathrm{s}$ using $\mathrm{Pt}$ and $\mathrm{Ag} / \mathrm{AgCl}$ (saturated in $\mathrm{KCl}$ ) as counter and reference electrodes, respectively. The CVs show two broad oxidation waves, labeled I and II, and two broad reduction waves, labeled IV and $\mathrm{V}$, due to formally $\mathrm{Ir}^{\mathrm{II}} / \mathrm{Ir}^{\mathrm{IV}}$ and $\mathrm{Ir}^{\mathrm{IV}} / \mathrm{Ir}^{\mathrm{V}}$ redox couples (occurring at same potentials), respectively. ${ }^{34,37}$ An additional current (point III in Figure 1C and 1D) is ascribed to the oxidation of water. The CVs in Figure 1C and 1D indicate that both the thin film and bilayer graphene coated with Ir NPs behave similarly. The control experiments with the plain graphene electrode were reported in previous work, ${ }^{38}$ indicating clearly an enhanced catalytic activity for the electrode decorated with Ir NPs. Therefore, it is possible that similar active species are present during the electrocatalytic oxidation of water to dioxygen on both the thin-film and iridium NP electrodes. It is generally accepted that these active sites are hydrated Ir-oxyhydroxides formed in situ during OER, ${ }^{39-41}$ where the Ir oxohydroxide-based OER is stable for high-current water electrolysis under acidic conditions. ${ }^{42}$

In order to determine the nature of the active species, the electronic structure modification that the electrodes undergo during the electrocatalytic oxidation of water was investigated by means of operando XAS. The electrocatalysts were characterized first using XAS in total fluorescence yield (TFY) mode at the $\operatorname{Ir} \mathrm{L}_{3}$-edge using a homemade in situ electrochemical cell; ${ }^{22}$ more details can be found in the Supporting Information (SI). Using a $100 \mathrm{~nm}$ thick $\mathrm{SiN}_{x}$ membrane, which is transparent to the incoming and out-going photons, it is possible to investigate the variations in the electronic structure using photon-in/photon-out (PIPO) techniques in the hard X-ray regime. An advantage of this approach is that it enables the study of electrochemical reactions with aqueous electrolytes (i.e., $100 \mathrm{mM} \mathrm{H}_{2} \mathrm{SO}_{4}$ ). Figure $2 \mathrm{~A}$ and $2 \mathrm{~B}$ show the detection scheme with the thinfilm and free-standing bilayer graphene decorated with Ir NPs. For both materials it is possible to perform measurements in TFY-XAS by collecting the photons emitted during the fluorescence decay following the absorption process; this signal comes from the surface and bulk of the materials. Therefore, TFY-XAS provides information associated with the whole electrode (bulk and surface) in the case of the Ir thin film. However, in the case of the NPs, the surface-to-bulk signal is enhanced by a factor of around 10 compared to the thin film electrode, despite the methodology not being a surface informative technique. Moreover, the free-standing graphene allows the collection of photoelectrons (by a hemispherical electron analyzer) from the side exposed to the electrolyte, thereby enabling the acquisition of photoelectron spectra (PES) ${ }^{43,44}$ Meanwhile, the thin-film electrode $(20 \mathrm{~nm})$ yields photoelectrons mostly from the side where the electrode is exposed to the incident X-ray photons, as a consequence of the short inelastic mean free path (IMFP) of the low energy photoelectrons accessible within the soft X-ray 

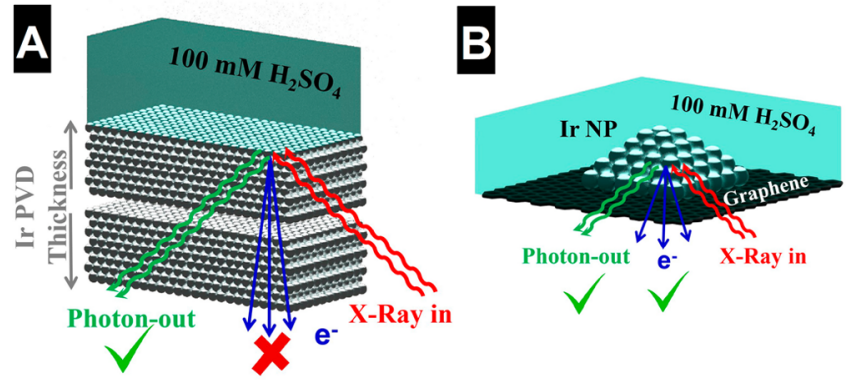

c

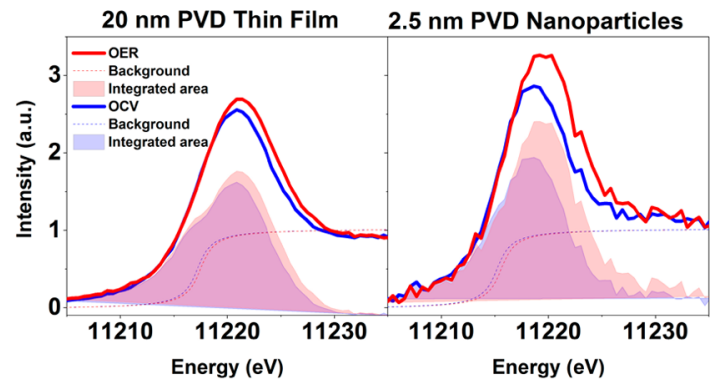

Figure 2. Schematic detection scheme using (A) a thin-film $\operatorname{IrO}_{x}$ electrode or (B) free-standing CVD bilayer graphene electrode decorated with $\mathrm{IrO}_{x}$ NPs. Spectra comparison at different potentials (OCV and OER at $-1.6 \mathrm{~V}$ vs $\mathrm{Ag} / \mathrm{AgCl}$ ) for the (C) thin-film $\mathrm{IrO}_{x}$ electrode $(20 \mathrm{~nm})$ and free-standing CVD bilayered graphene (BLG) electrode decorated with $\mathrm{IrO}_{x} 2.5 \mathrm{~nm}$ NPs.

regime (typically a few nanometers), as shown in Figure 2A. However, using $\mathrm{X}$-rays with higher energy (in the tender or hard X-ray regimen) the information depth can be enlarged at the price of less surface sensitivity. This fact makes it impossible to investigate the electrified solid-liquid interface of such a thick working electrode using soft X-ray PES in this manner. Note that while the short IMFP on soft X-ray PES is a significant technical challenge, the high near-surface sensitivity it offers in solids or liquids ${ }^{45-47}$ makes soft X-ray PES an excellent complement to TFY-XAS.
Figure 2C shows the $\operatorname{Ir} \mathrm{L}_{3}$-edge spectra collected under operando conditions. The $\mathrm{Ir}_{3}$-edge probes the dipole allowed transitions from a core $\operatorname{Ir} 2 p_{3 / 2}$ electron to the partially occupied Ir 5d and Ir 6sp orbitals, which are hybridized with the O $2 \mathrm{p}$ orbitals. ${ }^{38}$ Transitions to the $5 \mathrm{~d}$ orbitals are lower in energy and well separated from transitions to the $6 \mathrm{sp}$. These $2 \mathrm{p}$ to $5 \mathrm{~d}$ transitions give rise to the so-called white line. While the large lifetime broadening (about $5 \mathrm{eV}^{48}$ ) does not allow the discrimination of fine structure in the white line due to, for instance, transitions into $\mathrm{t}_{2 \mathrm{~g}}$-like and $\mathrm{e}_{\mathrm{g}}$-like $5 \mathrm{~d}$ orbitals, analysis of the white-line intensity can still give insight into the electronic structure of iridium. In particular, a sum rule relates the total number of $5 \mathrm{~d}$ holes to the integral area of the white line; ${ }^{11,38}$ that is, the white line is linearly proportional to the iridium oxidation state. ${ }^{48}$ Note that while the sum rule is a property of the dipole operator and rigorously holds ${ }^{49,50}$ for $\mathrm{L}_{3}$ $+\mathrm{L}_{2}$, previous work shows no change in the $\mathrm{L}_{3} / \mathrm{L}_{2}$ branching ratio for oxidized iridium compounds, making $\mathrm{L}_{3}$ alone sufficient for a white-line analysis. ${ }^{48}$ The ability of the bulk sensitive TFY-XAS measurements to reveal changes in average Ir oxidation states is apparent from Figure 2C. Using the maximum intensity of the $\mathrm{Ir} \mathrm{L}_{3}$ edge as a measure of average Ir oxidation state an increase in the number of Ir $5 \mathrm{~d}$ holes can be seen in both the thin-film and NP samples under anodic polarization. This increase in average oxidation state is reversed under open circuit voltage (OCV). Similar trends were reported previously by in situ characterization of iridated working electrodes. ${ }^{41-55}$ Note that the size effects observed in the spectra collected have no clear influence on the catalytic performance of the different electrodes under reaction conditions. We guess that it is a consequence that both planar electrode structures are not very different from one another and consequently the changes in the catalytic performance are not considerable. Before turning to a quantitative evaluation of this behavior, however, the details of the proportionality between white-line intensity and Ir oxidation state must be found. To establish a connection between the white-line intensity and the number of $5 \mathrm{~d}$ holes on Ir we analyzed a series of reference samples, including: $\mathrm{Ir}^{0}, \mathrm{IrCl}_{3}, \mathrm{IrO}_{2}$, and $\mathrm{IrO}_{x}$
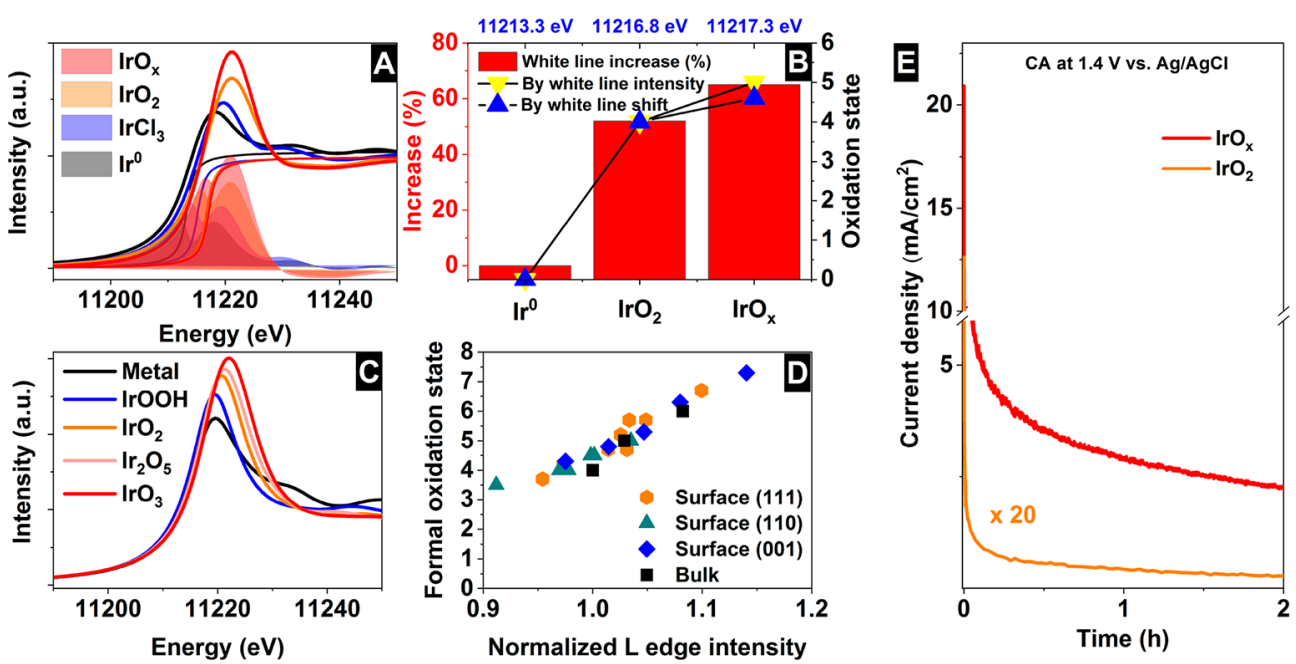

Figure 3. (A) $\mathrm{Ir} \mathrm{L}_{3}$ spectra of different reference samples including the background subtraction and remaining signal related to the sum-rule of the Ir $5 \mathrm{~d}$ electron-holes. (B) Increase of integrated area relative to $\mathrm{IrCl}_{3}$ and absolute oxidation state deduced from the relative increase of the area or the white line position. Calculated (C) Ir $\mathrm{L}_{3}$-edge spectrum of the surface and bulk of an iridium oxides (see Figure S10 for results including a Hubbard $U$ ) and (D) correlation between computed $\mathrm{L}_{3}$-edge maximum intensity and formal oxidation state. (E) Catalytic performance comparison of the $\mathrm{IrO}_{x}$ and $\mathrm{IrO}_{2}$ at $1.4 \mathrm{~V}$ vs $\mathrm{Ag} / \mathrm{AgCl}$ in deaerated $100 \mathrm{mM} \mathrm{H}_{2} \mathrm{SO}_{4}$ with $\mathrm{N}_{2}$ continually bubbled in the electrolyte. 
(reference samples details can be found in the SI). ${ }^{54}$ An iridium foil was used for $\mathrm{Ir}^{0}$. $\mathrm{IrCl}_{3}$ powder was used as an $\mathrm{Ir}^{\mathrm{III}}$ reference, and $\mathrm{IrO}_{2}$ rutile-type powder was taken as an $\mathrm{Ir}^{\mathrm{IV}}$ reference. In addition, an amorphous $\mathrm{IrO}_{x}$ catalyst rich in active species ${ }^{40}$ was used to compare with the catalysts used in this work, owing to higher electrocatalytic activity compared to the $\mathrm{IrO}_{2}$ rutile. Note that the $\mathrm{Ir}^{0}$ (foil) white line can be artificially enhanced due to the existence of a native oxide layer, and because this spectrum is collected in TFY mode, selfabsorption effects are also possible. However, the oxide layer is not a problem since it is thin compared to the bulk with minor contribution to the white-line intensity.

Figure 3A shows the $\mathrm{Ir} \mathrm{L}_{3}$ spectra of the reference samples including the background subtraction and remaining signal, which relates the number of Ir 5d holes to the integral area of the white line. ${ }^{48}$ These measurements clearly show an increase in the $\mathrm{Ir}_{3}$-edge white-line intensity for the different samples following the trend: $\operatorname{Ir}^{0}<\mathrm{IrCl}_{3}<\mathrm{IrO}_{2}<\mathrm{IrO}_{x}$. Moreover, in Figure $3 \mathrm{~B}$ the maximum intensity of the white-line is linearly correlated with the integral intensity and, therefore, Ir oxidation state. Thus, for simplicity we employ the maximum white-line intensity as a measure of the Ir oxidation state. Similarly, the $\mathrm{Ir}_{3}$-edges computed using the Bethe-Salpeter equation show the same trend continues through the bulk oxides $\mathrm{Ir}_{2} \mathrm{O}_{5}$ and $\mathrm{IrO}_{3}$ (Figure 3C,D); see SI for more details (Figure S4). From the white-line integration of the experimental data, Figure $3 \mathrm{~B}$ shows the percent increase in the Ir $5 \mathrm{~d}$ density of electron-holes referred to $\mathrm{IrCl}_{3}$ and the equivalent oxidation state. Therefore, an oxidation state of +4 corresponds to an increase of $\sim 22 \%$ of the white-line intensity with respect to $+3\left(\mathrm{IrCl}_{3}\right.$ sample), and a change of $\sim 32 \%$ for the case of $\mathrm{IrO}_{x}$ corresponding to a +4.7 average oxidation state. This increase is supported by its comparison with $\mathrm{Ir}^{0}$, where an increase of $52 \%$ of the white-line intensity is found for +4 and $65 \%$ for $\mathrm{IrO}_{x}$, corresponding to a +4.6 average oxidation state. Performing a similar quantification using the simulated data shows the maximum white-line intensity changes linearly with the Löwdin charge on Ir in the bulk phases as well as across various surface $\mathrm{Ir}$ species bound to $\mathrm{O}$, $\mathrm{OH}, \mathrm{OOH}$, and $\mathrm{OO}$ on $\mathrm{IrO}_{2}$ surfaces spanning formal oxidation states from $<$ IV to $>$ VII (see SI for details, Figures S5 and S6; also note these results are incentive for the inclusion of a Hubbard $U$; see Figure S10), suggesting no significant changes in intensity variation should be expected at higher oxidation states for the iridium oxyhydroxides. One can also consider that the change in the oxidation can often be correlated to the shift in the peak position, using this approach an average experimental oxidation state of +4.3 is found for $\mathrm{IrO}_{x}$, similar to the integration of the white line (Figure 3C). Both approaches yield an average oxidation state for $\operatorname{IrO}_{x}$ under vacuum $>\mathrm{IV}$ suggesting the presence of $\operatorname{Ir}^{\mathrm{V}}$, in agreement with the $\mathrm{Ir}^{\mathrm{V}}$ reported to appear in $\mathrm{IrO}_{x}$ during reaction conditions using a similar analysis, but significantly less than the $\mathrm{Ir}^{\mathrm{VI}}$ reported ${ }^{11}$ to appear in Ni-leached $\mathrm{IrNiO}_{x}$. According to Figure $3 \mathrm{E}$ it is clear that the formation of such active species has a positive impact in the electrocatalytic performance of the sample containing more Ir 5d holes. However, the increased amorphization of the $\mathrm{IrO}_{x}$ surfaces had been ascribed as a possible reason for the increased electrocatalytic activity during the OER, ${ }^{56,57}$ which can lead to the formation of $\mathrm{Ir}^{\mathrm{V}}$ active sites. Thus, the higher white-line intensity of the NPs compared to the thin films is likely due to incomplete oxidation of the bulk in thick films. ${ }^{58,59}$ To see if evidence for such high oxidation state Ir emerges for Ir NPs and thin films under reaction conditions, we return to in situ measurements.

Figure 4 shows how the measured white-line intensities change with applied bias referred to the OCV spectra, which is

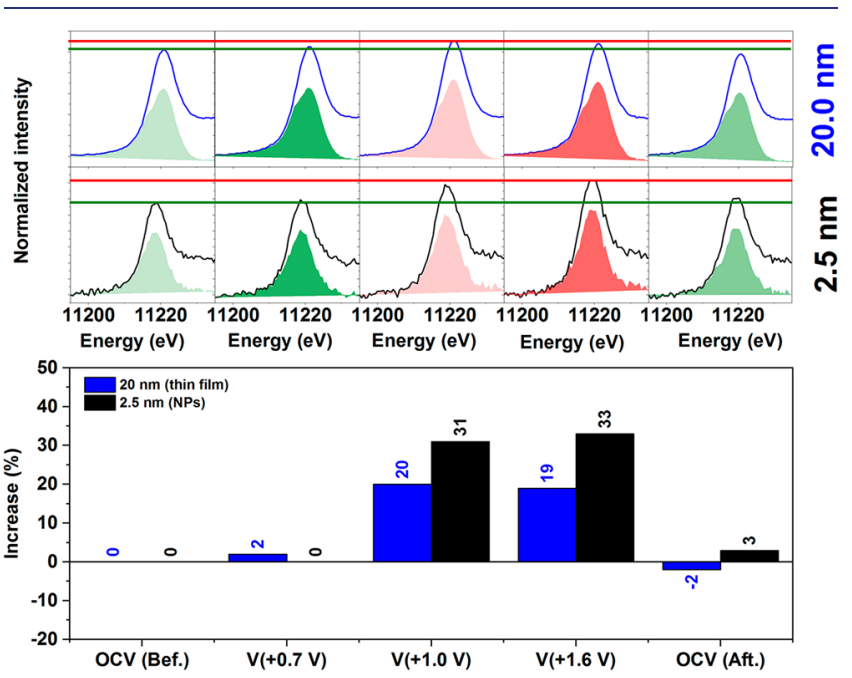

Figure 4. Top: Spectra at different potential for the thin-film $\operatorname{IrO}_{x}$ electrode $(20 \mathrm{~nm})$ and free-standing CVD bilayered graphene (BLG) electrode decorated with $\mathrm{IrO}_{x} 2.5 \mathrm{~nm}$ NPs (top). Bottom: Relative increase of the hole density against the electrode potential recorded during the in situ characterization.

used as reference. The spectra were collected under chronoamperometric (CA) control, and $\sim 1 \mathrm{~h}$ was required to record each $\mathrm{Ir} \mathrm{L}_{3}$-edge spectrum. This fact, together with the constant current observed under the applied potential, verifies that the spectra where collected under steady state conditions, which is important to ensure their fidelity. The surfaces likely remain partially oxidized after the $\mathrm{CV}$ activation steps ${ }^{60}$ making an assignment to $\mathrm{Ir}^{\mathrm{III}}$ more appropriate, as a consequence of the surface irreversible oxidation state, as confirmed by XPS below. At $1.0 \mathrm{~V}, \operatorname{Ir}^{\mathrm{IV}}$ has become the oxidation state, which is further supported by the CVs of the film and NPs showing $1.0 \mathrm{~V}$ the transition assigned to $\operatorname{Ir}^{\mathrm{IV}} / \mathrm{Ir}^{\mathrm{V}}$. At $1.0 \mathrm{~V}$ the near-surface region is then expected to be $\mathrm{Ir}^{\mathrm{IV}}$. The higher white-line intensities confirm oxidation, with the $\sim 30 \%$ increase for the Ir NPs in line with an increase to +4.5 , assuming $\mathrm{Ir}^{\mathrm{III}}$ to start. The higher white-line intensity of the NPs compared to the thin films is likely due to incomplete oxidation of the bulk of the $20 \mathrm{~nm}$ thin films. ${ }^{58,59}$ At $1.6 \mathrm{~V}$, though no further increase in white-line intensity is observed for the thin films, the NPs show an additional $\sim 4 \%$ increase above that observed at $1.0 \mathrm{~V}$ suggesting the coexistence of $\operatorname{Ir}^{\mathrm{IV}} /$ $\operatorname{Ir}^{\mathrm{V}}$, or higher oxidation states, on the catalyst surface. The reverse scan back to OCV shows the process reversibility. To gain a better understanding of what these species may be, we turned to $a b$ initio calculations.

In order to provide a better description of the observed changes in the white-line spectra, these reference and operando measurements were compared with the DFT calculated $\mathrm{Ir} \mathrm{L}_{3}$ edge spectrum (details can be found in the SI). We begin with the lowest energy, in vacuum, $\mathrm{IrO}_{2}$ surface, (110), as a model for the DFT calculations. ${ }^{60}$ The surface was first fully hydrogenated as shown in Figure 5. It was then successively oxidized by following a series of proton coupled electron transfers to explore the adsorbates argued to be present under OER conditions; ${ }^{60}$ see Figure 5 . The $\mathrm{Ir}_{3}$-edge white-line 

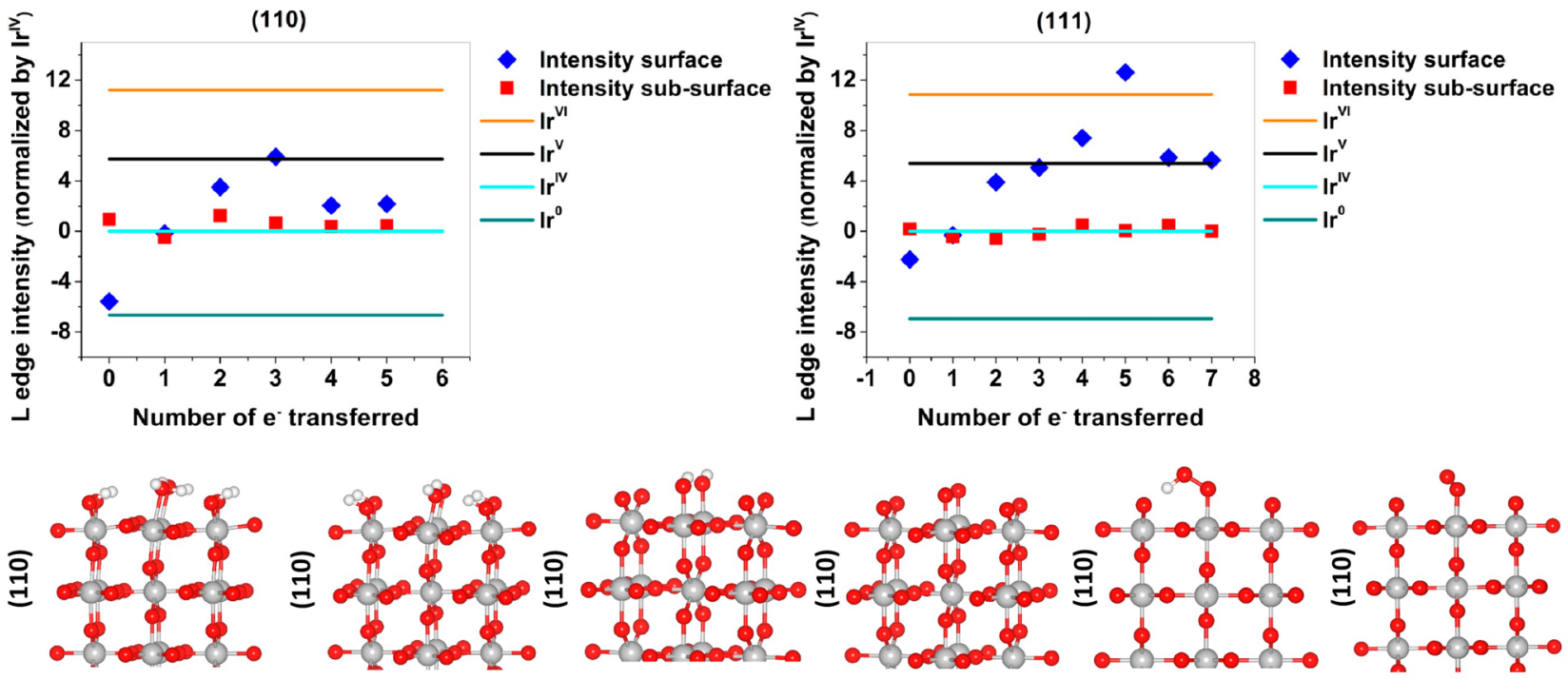

$\mu_{2} \mathrm{OH}, \mu_{1} \mathrm{H}_{2} \mathrm{O}$

$\mu_{2} \mathrm{OH}, \mu_{1} \mathrm{OH}$

$\mu_{2} \mathrm{O}, \mu_{1} \mathrm{OH}$

$\mu_{2} \mathrm{O}, \mu_{1} \mathrm{O}$

$\mu_{2} \mathrm{O}, \mu_{1} \mathrm{OOH}$

$\mu_{2} \mathrm{O}, \mu_{1} \mathrm{OO}$

\section{Increasing number of electron transfers}

Figure 5. Plots of $\mathrm{L}_{3}$ intensity vs electron transfers for (110) and (111) surfaces of $\mathrm{IrO}_{2}$. On the bottom the different figures are shown for the (110) surfaces. (111) structures are shown in the SI.
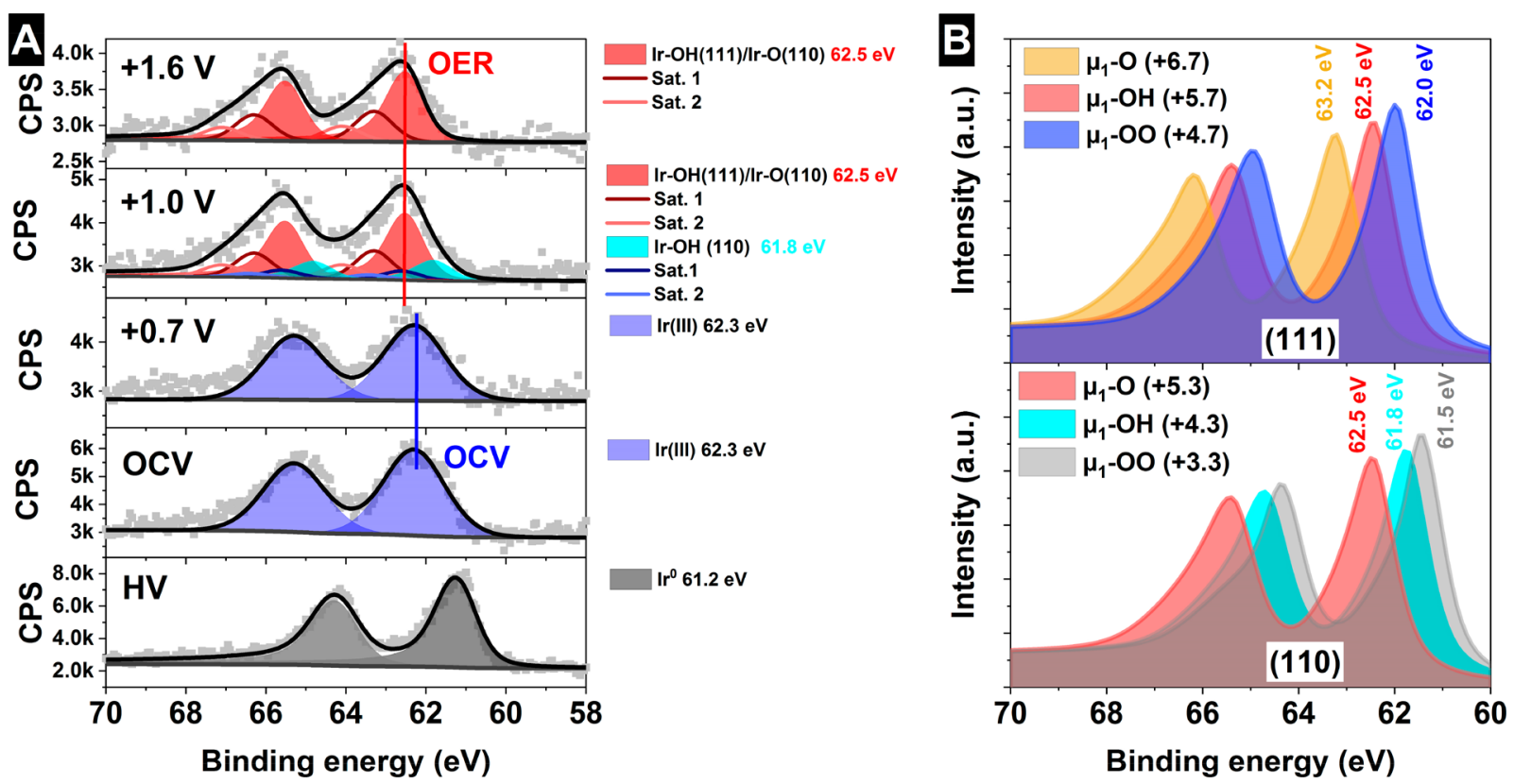

Figure 6. Operando measurements in $100 \mathrm{mM} \mathrm{H}_{2} \mathrm{SO}_{4}$ of the free-standing bilayer graphene decorated with $\mathrm{IrO}_{x} \mathrm{NPs}_{\text {at different potentials vs } \mathrm{Ag} /}$ $\mathrm{AgCl}(\mathrm{A})$. Ir $4 \mathrm{f}$ (B) simulated $\mathrm{Ir} 4 \mathrm{f}$ spectra of species identified in the $\mathrm{Ir}_{\mathrm{L}}$ edge analysis with the formal oxidation state in brackets.

intensities of these surfaces were computed and plotted against the number of electrons transferred from the hydrogenated surface unit cell to reach the desired surface oxidation state. From Figure 5 it can be seen that only the surface Ir atoms respond to the oxidation, with the first subsurface layer already converged to the $\mathrm{L}_{3}$-edge white-line intensity of bulk $\mathrm{Ir}^{\mathrm{IV}}$. The average surface oxidation state can be seen to increase from a white-line intensity below $\operatorname{Ir}^{\mathrm{IV}}$ when $\mu_{1}-\mathrm{H}_{2} \mathrm{O}$ and $\mu_{2}-\mathrm{OH}$ are present-where the subindex indicates the number of iridium atoms bound to an oxygen atom-to a value consistent with bulk $\mathrm{Ir}^{\mathrm{V}}$ when $\mu_{1}-\mathrm{O}$ and $\mu_{2}-\mathrm{O}$ are present. The former is close to the +3.5 average formal oxidation state for the surface $\mathrm{Ir}$ atoms found by simple bound counting.

Removing $\mathrm{H}^{+}$and $\mathrm{e}^{-}$from $\mu_{1}-\mathrm{H}_{2} \mathrm{O}$ on the (110) surface yields a surface with $\mu_{1}-\mathrm{OH}$ and $\mu_{2}-\mathrm{OH}$ that is predicted to be stable up to $0.7 \mathrm{~V} .^{60}$ The average formal surface oxidation state of Ir on this surface is $+\mathrm{IV}$, in-line with the computed $\mathrm{L}_{3}$-edge white-line intensity, Figure 5. At $0.7 \mathrm{~V}$ the surface termination is predicted to transform into $\mu_{1}-\mathrm{OH}$ and $\mu_{2}-\mathrm{O}$, with an average Ir surface oxidation state of +4.5 , in general agreement with the experimental results on the NPs. Above $1.2 \mathrm{~V}$ both a surface $\mu_{1}-\mathrm{O}$ or $\mu_{1}-\mathrm{OO}$ have been predicted to be stable. ${ }^{39,60}$ 
Of these, the $\mu_{1}$-O appears more likely on the NP surface owing to the small increase in white-line intensity observed experimentally between 1.0 to $1.6 \mathrm{~V}$, which is consistent with the increase in iridium formal oxidation state and the computed white-line intensity for transitioning from $\mu_{1}-\mathrm{OH}$ to $\mu_{1}$-O. The $\mu_{1}$-OO (and $\mu_{1}-\mathrm{OOH}$ ) show reduced white-line intensities relative to $\mu_{1}-\mathrm{OH}$ and $\mu_{1}-\mathrm{O}$, and while we observed no evidence for such a reduction in intensity, it has been previously observed on $\mathrm{IrO}_{x} \mathrm{NPs}$ at high applied potential. ${ }^{61}$

We also considered the possibility that the NPs facet during anodic polarization, as above $1.1 \mathrm{~V}$ the (111) surface is thermodynamically favored. ${ }^{60}$ Following the same methodology as above, Figure 5 shows the $\operatorname{Ir~} \mathrm{L}_{3}$-edge white-line intensities as a function of the number of electrons transferred starting from a fully hydroxylated (111) surface; see SI for structures (Figure S5). Here, though more points are included owing to the presence of four $\mu_{2}-\mathrm{OH}$ species in the unit cell, a similar trend emerges as found for the (110) surface, with the Ir $\mathrm{L}_{3}$-edge white-line intensities reaching higher values due to the increased formal surface iridium oxidation states on the (111) vs (110) surface. In particular, the Ir bound to $\mu_{1}-\mathrm{O}$ reaches a formal oxidation state exceeding $\mathrm{Ir}^{\mathrm{VI}}$. Such a species is predicted to appear once the bias reaches $1.1 \mathrm{~V}$; above $1.2 \mathrm{~V}$ $\mu_{1}$-O may transform into a $\mu_{1}$-OO. ${ }^{60}$ While we see no drop in white-line intensity on the NPs supporting the formation of $\mu_{1^{-}}$$\mathrm{OO}$, we cannot completely rule out the appearance of $\mathrm{Ir}^{\mathrm{VI}}$ from XAS alone. Thus, we turned to XPS, as this technique apart from providing complementary information on the occupied orbitals is also more sensitive to the surface states.

As a surface informative technique, XPS compliments the bulk sensitive XAS and offers the opportunity to gain deeper knowledge about the mechanism mediating the electrochemical oxidation of water on iridium oxide. The electronic structure of the $\mathrm{IrO}_{x} \mathrm{NPs}$ on graphene was investigated at the Ir $4 \mathrm{f}$ core level using the facilities and in situ electrochemical flow cells described in the SI. ${ }^{44}$ The Ir $4 \mathrm{f}$ spectra depending on the applied potential are shown in Figure 6A, as well as its comparison with the reference samples (bottom spectra) and the computed line shapes for the relevant species inferred through the XAS analysis (see Figures S7 and S8). Computed XPS binding energies are summarized in Table $\mathrm{S} 1$.

At, and below, $0.7 \mathrm{~V}$ the NPs are composed of predominantly bulk $\mathrm{Ir}^{\mathrm{III}}$, with an Ir $4 \mathrm{f}$ binding energy of 62.3 $\mathrm{eV}^{62}$ Once the electrode is polarized to $1.0 \mathrm{~V}$, we know from XAS that the NPs are oxidized to $\mathrm{Ir}^{\mathrm{IV}}$, and possibly higher. Note that the lack of a linear shift in the measured Ir $4 \mathrm{f}$ with applied potential indicates good electrical contact between the graphene and Ir NPs. In addition, the change in the spectrum shape is in good agreement with a close interaction with the electrolyte and correct electrochemical performance, i.e. no gas-bubble accumulation on the electrode surface hindering the electrical contact. From the simulations we find that Ir atoms on the surface of $\mathrm{IrO}_{2}$ show normal $\mathrm{Ir} 4 \mathrm{f}$ binding energy shifts up to formal Ir oxidation states of, at least, 7.3 (see Table $\mathrm{S} 1$ ), with the average formally $\mathrm{Ir}^{\mathrm{V}}$ and $\mathrm{Ir}^{\mathrm{VI}}$ species appearing near $\sim 62.2 \mathrm{eV}$ and $\sim 62.7 \mathrm{eV}$, respectively. Thus, the Ir $4 \mathrm{f}$ shift is a good measure of the iridium oxidation state for Ir atoms in a conductive matrix. However, this conductive matrix also influences the $\mathrm{Ir} 4 \mathrm{f}$ line shape, making accurate speciation challenging. The computed $\mathrm{Ir} 4 \mathrm{f}$ spectra all show complex line shapes due to conduction band screening (see Figure 6B for computed XPS), similar to that observed in rutile-type $\mathrm{IrO}_{2},{ }^{10,63}$ where shakeup satellites are required to fit the spectral envelope. The line shape varies systematically with the formal oxidation state of Ir, with the primary satellite shifting closer to the main line with increasing iridium oxidation state; see Figure $6 \mathrm{~B}$. Noting this behavior allows a suitable fit model to be developed.

Using this fit model we see that, at an applied bias of $1.0 \mathrm{~V}$, peaks appear at 61.8 and $62.5 \mathrm{eV}$, both of which show strong conduction band screening. The first of these peaks is consistent with the $\mathrm{Ir}^{4.3}$ bound to $\mu_{1}-\mathrm{OH}$ on the (110) surface. The species at $62.5 \mathrm{eV}$ is consistent with the $\mathrm{Ir}^{5.3}$ bound to $\mu_{1}$ $\mathrm{O}$ on the (110) surface or the $\mathrm{Ir}^{5.7}$ bound to $\mu_{1}-\mathrm{OH}$ (or $\mu_{1}$ $\mathrm{OOH})$ on the (111) surface. Thus, at $1.0 \mathrm{~V}$ the near-surface region appears to be dominated by $\operatorname{Ir}^{\mathrm{IV}} / \mathrm{Ir}^{\mathrm{V}}$ and $\mu_{1}-\mathrm{OH} / \mu_{1}-\mathrm{O}$. These findings are in general agreement with predictions based on $a b$ initio atomistic thermodynamics. ${ }^{60}$ Details of the parameters used for fitting the spectra can be found in the SI (Table S2), where a Shirley ${ }^{64}$ background is used. Note the fact that only a minimal contribution of remaining $\operatorname{Ir}^{\mathrm{IV}}$ species were detected in the Ir $4 \mathrm{f}$ peaks under OER, indicating that this signal is produced by atoms buried in the bulk of the catalyst (i.e., not reacting with the water molecules in the electrolyte). Meanwhile, the $\mathrm{Ir}^{\mathrm{V}}$ signal comes mostly from Ir atoms located in the surface and near-surface of the nanoparticles. Thus, the combination of nanostructured electrodes with surface informative photoelectron spectroscopy is an effective tandem for increasing the information on the electrified interface during the electrocatalytic processes, which can be applied to other reactions of interest.

Under OER $(-1.6 \mathrm{~V}$ vs $\mathrm{Ag} / \mathrm{AgCl})$ conditions the species at $62.5 \mathrm{eV}$ becomes the dominant species and no higher binding energy component is found. This suggests that a large fraction of the high oxidation state species is present, being not specific to a unique potential, as the bias increased from 1.0 to $1.6 \mathrm{~V}$ vs $\mathrm{Ag} / \mathrm{AgCl}$, as shown in Figure 6A, in agreement with the XASTFY operando measurements. This rules out this species as a reactive intermediate, because it would already react and produce oxygen at $-1.0 \mathrm{~V}$ vs $\mathrm{Ag} / \mathrm{AgCl}$. With XPS, however, we can rule out the possibility of Ir oxidation states of $\mathrm{Ir}^{\mathrm{VI}}$ and above since these would appear at higher binding energies than those observed. Thus, taking XPS and XAS together we tentatively assign the species appearing at $62.5 \mathrm{eV}$ to a formally $\mathrm{Ir}^{\mathrm{V}}$ species bound to $\mu_{1}-\mathrm{O}$ on the (110) surface. While small amounts of the Ir at this high binding energy has also been observed in both ex situ ${ }^{65}$ and in situ ${ }^{66}$ studies, the surface model system employed in this work allows us to show the formally $\mathrm{Ir}^{\mathrm{V}}$ species is the dominant surface species under the OER $(-1.6 \mathrm{~V}$ vs $\mathrm{Ag} / \mathrm{AgCl})$, in good agreement with previous results, ${ }^{66}$ a key aspect in materials with a high surface-to-bulk ratio. ${ }^{67}$ Unlike the previous XPS experiments performed in gasphase conditions, ${ }^{66}$ the results reported herein were conducted in the presence of bulk aqueous electrolyte. The enhanced changes in the spectra observed in this work may then be a consequence of better interface hydration. The performance of the water vapor in situ cell and the quality of the spectra collected were significantly improved in our group in recent years. ${ }^{40,68-70}$ However, these experiments were not performed in the presence of a bulk aqueous electrolyte, which can potentially yield different results from those found in a typical three-electrode benchtop experiment. In addition, the experimental conditions reported here are collected under the same environmental conditions than in the case of the operando XAS experiments making possible a direct comparison of the results obtained with both approaches. It is not 
doable between the different studies present in the literature because they combine different catalysts with different EC-cells designs, electrolytes, and experimental conditions making a direct comparison between them undesirable. When combined with $a b$ intio simulation, this allows a more definitive assignment to be made. Moreover, from the simulations we see that, at such high formal Ir oxidation states, the $\mu_{1}-\mathrm{O}$ species bound to $\mathrm{Ir}^{\mathrm{V}}$ may also be referred to as $\mathrm{O}^{\mathrm{I}-}$ owing to the spin density on oxygen. ${ }^{71}$ This electron deficiency on $\mu_{1}-\mathrm{O}$ makes the oxygen susceptible to nucleophilic attack, ${ }^{11,39,63,72}$ suggesting the high activity of the Ir NPs is linked to electronhole enrichment on $\mu_{1}$-O.

To verify the reactivity of the $\mu_{1}-\mathrm{O}(\mathrm{H})$ and the role of iridium oxidation state on electrocatalytic performance, we computed the activation energy for $\mathrm{O}-\mathrm{O}$ coupling on the (110) surface while varying Ir oxidation state within the range observed experimentally. This step was chosen, as it is believed to be rate limiting ${ }^{72}$ and can be approximated as a chemical step wherein an $\mathrm{O}-\mathrm{O}$ bond is formed between $\mu_{1}-\mathrm{O}$ and $\mathrm{H}_{2} \mathrm{O}^{73}$ (Note that while the exact values of the these energies may differ with solvent, their trend is expected to remain qualitatively correct. $^{73}$ ) Figure 7 shows the computed

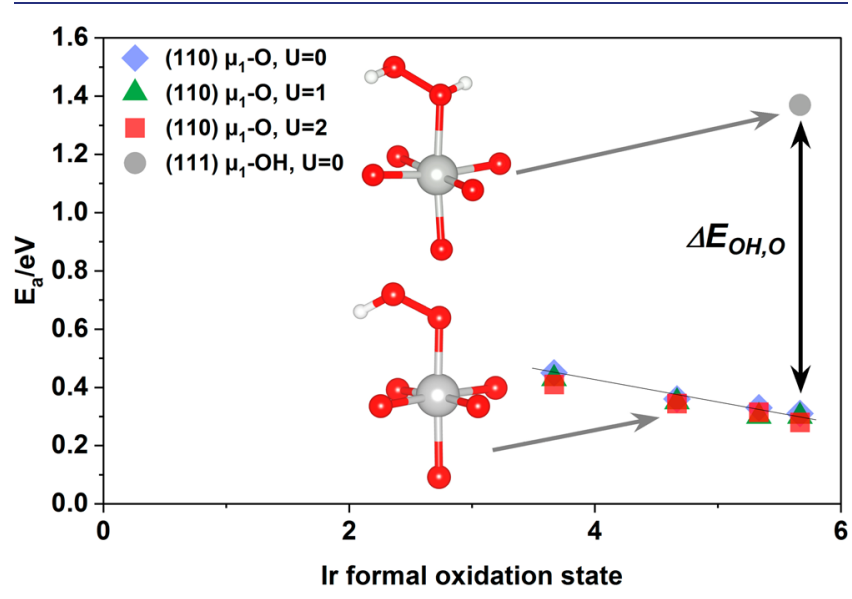

Figure 7. Heat of reaction computed for $\mathrm{O}-\mathrm{O}$ bond formation between $\mathrm{H}_{2} \mathrm{O}$ on the (111) surface and $\mu_{1}-\mathrm{O}(\mathrm{H})$ on the (110) surface. The heat of reaction represents the minimum activation energy for the reaction. $\operatorname{The} \operatorname{Ir}(\mathrm{V})-\mathrm{OH}$ on the (111) surface reacts to produce bound $\mathrm{HOOH}$ and shows a high activation energy despite the high formal Ir oxidation state. On the (110) surface the $\operatorname{Ir}(\mathrm{V})-\mathrm{O}$ reacts with $\mathrm{H}_{2} \mathrm{O}$ to form $\mu_{1}-\mathrm{OOH}$ and shows an activation energy more than $1 \mathrm{eV}$ lower than that associated with $\operatorname{Ir}(\mathrm{V})-\mathrm{OH}$, the difference labeled $\Delta E_{\mathrm{OH}, \mathrm{O}}$. Varying the oxidation state of Ir bound to $\mu_{1}-\mathrm{O}$ results in a linear change in the computed activation energy. See also Figure S9.

activation energies for $\mathrm{O}-\mathrm{O}$ bond formation through this process on the (110) surface plotted as a function of formal Ir oxidation state, along with the corresponding heat of reaction between $\mathrm{H}_{2} \mathrm{O}$ and $\mathrm{Ir}(\mathrm{V}) / \mu_{1}-\mathrm{OH}$ on the (111) surface, which is the lower bound on the activation energy; see Figure S9 for structures. Inspection of Figure 7 reveals $\mathrm{O}-\mathrm{O}$ bond formation between $\mathrm{H}_{2} \mathrm{O}$ and $\operatorname{Ir}(\mathrm{V}) / \mu_{1}-\mathrm{OH}$ on the (111) surface is slow, with a thermodynamic barrier in excess of $1.4 \mathrm{eV}$ associated with the formation of the adsorbed $\mathrm{HO}-\mathrm{OH}$ shown in Figure 7. This picture contrasts the high activity of $\operatorname{Ir}(\mathrm{V}) / \mu_{1}-\mathrm{O}$ on the (110) surface. In this case, the activation energy to $\mathrm{O}-\mathrm{O}$ coupling is only $0.33 \mathrm{eV}$ because the hole character on $\mu_{1}-\mathrm{O}$ facilitates $\mathrm{O}-\mathrm{O}$ bond formation. Thus, Ir oxidation state alone does not control the activation energy for $\mathrm{O}-\mathrm{O}$ coupling, and electron-deficient oxygen appears to be needed. When electron-deficient $\mu_{1}-\mathrm{O}$ is present, however, varying the oxidation state of the iridium bound to the $\mu_{1}$-O involved in $\mathrm{O}-\mathrm{O}$ coupling shows the $\mathrm{Ir}$ oxidation state does play a prominent role. In Figure 7 this was done by introducing a surface Ir vacancy, subsurface $\mathrm{O}$ vacancy, or substituting subsurface $\mathrm{O}$ with $\mathrm{H}$; see Figure S9. The result is that the computed activation energy drops almost linearly with increasing formal Ir oxidation state; see Figure 7. Introducing a Hubbard $U$ correction does not alter this observation. Thus, it appears the $\mu_{1}$-O that can appear when the Ir oxidation state reaches $\mathrm{V}+$ facilitates $\mathrm{O}-\mathrm{O}$ bond formation and its activity is sensitive to the Ir oxidation state.

With this picture of the catalytic performance, it is useful to return to the measured spectra. When the XPS and XAS measurements are compared an important aspect of the active state of the material can be seen. The relative thickness of the electron-hole enrichment beyond $\operatorname{Ir}^{\mathrm{IV}}$ is confined to the nearsurface region, while $\mathrm{Ir}^{\mathrm{IV}}$ may extend through the bulk. XPS shows the surface and near-surface of the NPs are dominated by the formation of active $\mathrm{Ir}^{\mathrm{V}+}\left(\right.$ or $\left.\mathrm{O}^{\mathrm{I}-}\right)$ species that are active in the electrocatalytic oxidation of water. These active species contribute ca. $\sim 4 \%$ to the overall $\mathrm{Ir}_{3}$ white-line intensity observed for the NPs when increasing the bias from 1.0 to 1.6 $\mathrm{V}$ vs $\mathrm{Ag} / \mathrm{AgCl}$, while the $\mathrm{Ir}^{\mathrm{IV}}$ bound to $\mu_{3}-\mathrm{O}$ species located in the bulk dominate the $\sim 30 \%$ increase in white-line intensity seen when increasing the bias from 0.6 to $1.0 \mathrm{~V}$ vs $\mathrm{Ag} / \mathrm{AgCl}$. By contrast, for the $20 \mathrm{~nm}$ films, surface oxidation past $\mathrm{Ir}^{\mathrm{IV}}$ cannot be discerned from the bulk oxidation to $\operatorname{Ir}^{\mathrm{IV}}$ owing to the overwhelming bulk signal.

\section{CONCLUSIONS}

In summary, the combination of $a b$ initio calculations, XA and $\mathrm{PE}$ spectroscopies, and nanofabrication of thin-film $\mathrm{IrO}_{x}$ and free-standing graphene decorated $\mathrm{IrO}_{x} \mathrm{NP}$ electrodes provided relevant information related to the active sites of iridium-based electrocatalysts in the kinetically sluggish OER. It was found that the electrocatalytic activity of $\mathrm{IrO}_{x}$ is ascribed to the formation of formally $\mathrm{Ir}^{\mathrm{V}}$ species bound to $\mu_{1}-\mathrm{O}$, where, due to the electron deficiency of these Ir sites, the $\mu_{1}-\mathrm{O}$ on the surface of the electrocatalyst that is susceptible to nucleophilic attack by water. Our results show that the potential-dependent oxidation state changes in the $\mathrm{IrO}_{x}$ extend through the bulk for oxidation states below $\mathrm{Ir}^{\mathrm{V}}$ but are constrained to the nearsurface region for higher oxidation states, suggesting bulk oxidation is limited. Thus, the higher surface-to-bulk ratio of nanostructured materials enhances iridium usage and the participation of a significant larger amount of surface and nearsurface active $\mu_{1}$-O. In addition we provide evidence using bulk electrolyte for these changes using surface informative XPS, which is in good agreement with the bulk sensitive XAS-TFY measurements yielding a direct link between surface and bulk effects in electrocatalytic OER. The different contribution of bulk and surface was discriminated, where the bulk maintains $\operatorname{Ir}^{\mathrm{IV}}$ character, while the surface undergoes oxidation to $\operatorname{Ir}^{\mathrm{V}}$.

\section{ASSOCIATED CONTENT}

\section{Supporting Information}

The Supporting Information is available free of charge at https://pubs.acs.org/doi/10.1021/jacs.1c01655. 
Experimental details including sample and electrolyte preparation, reference samples, instrumental details, operando electrochemical cells description, beamlines and DFT calculation details. Pictures of the operando electrochemical cells. Supplementary figures including SEM images of the free-standing graphene electrode, balls and sticks structure-models used for the DFT calculations, DFT calculations of the Ir $4 \mathrm{f}$ main peak and satellite position depending on the oxidation state, photoelectron spectra of the transmission properties of the free-standing graphene. Tables including computed and XPS fitting parameters (PDF)

\section{AUTHOR INFORMATION}

\section{Corresponding Authors}

Juan-Jesús Velasco-Vélez - Department of Heterogeneous Reactions, Max Planck Institute for Chemical Energy Conversion, Mülheim an der Ruhr 45470, Germany; Department of Inorganic Chemistry, Fritz-Haber-Institut der Max-Planck-Gesellschaft, Berlin 14195, Germany; Email: velasco@fhi-berlin.mpg.de

Travis E. Jones - Department of Inorganic Chemistry, FritzHaber-Institut der Max-Planck-Gesellschaft, Berlin 14195, Germany; (1) orcid.org/0000-0001-8921-7641; Email: trjones@fhi-berlin.mpg.de

\section{Authors}

Emilia A. Carbonio - Department of Inorganic Chemistry, Fritz-Haber-Institut der Max-Planck-Gesellschaft, Berlin 14195, Germany; Helmholtz-Center Berlin for Materials and Energy, BESSY II, Berlin 12489, Germany

Cheng-Hao Chuang - Department of Physics, Tamkang University, New Taipei City 25137, Taiwan; 자이.org/ 0000-0001-8161-1521

Cheng-Jhih Hsu - Department of Physics, Tamkang University, New Taipei City 25137, Taiwan

Jyh-Fu Lee - National Synchrotron Radiation Research Center, Hsinchu 30076, Taiwan

Rosa Arrigo - School of Sciences, University of Salford, Environment and Life, M5 4WT Manchester, U.K.

Michael Hävecker - Department of Heterogeneous Reactions, Max Planck Institute for Chemical Energy Conversion, Mülheim an der Ruhr 45470, Germany; Department of Inorganic Chemistry, Fritz-Haber-Institut der Max-PlanckGesellschaft, Berlin 14195, Germany

Ruizhi Wang - Department of Engineering, University of Cambridge, Cambridge CB3 OFA, U.K.; $\odot$ orcid.org/00000002-3914-8649

Milivoj Plodinec - Department of Inorganic Chemistry, FritzHaber-Institut der Max-Planck-Gesellschaft, Berlin 14195, Germany; Rudjer Boskovic Institute, HR-10000 Zagreb, Croatia

Feng Ryan Wang - Department of Chemical Engineering, University College London, London WC1E7JE, U.K.

Alba Centeno - Graphenea, San Sebastian 20018, Spain

Amaia Zurutuza - Graphenea, San Sebastian 20018, Spain

Lorenz J. Falling - Department of Inorganic Chemistry, FritzHaber-Institut der Max-Planck-Gesellschaft, Berlin 14195, Germany; $\odot$ orcid.org/0000-0002-2622-5166

Rik Valentijn Mom - Department of Inorganic Chemistry, Fritz-Haber-Institut der Max-Planck-Gesellschaft, Berlin 14195, Germany; ○ orcid.org/0000-0002-5111-5591
Stephan Hofmann - Department of Engineering, University of Cambridge, Cambridge CB3 OFA, U.K.

Robert Schlögl - Department of Heterogeneous Reactions, Max Planck Institute for Chemical Energy Conversion, Mülheim an der Ruhr 45470, Germany; Department of Inorganic Chemistry, Fritz-Haber-Institut der Max-PlanckGesellschaft, Berlin 14195, Germany

Axel Knop-Gericke - Department of Heterogeneous Reactions, Max Planck Institute for Chemical Energy Conversion, Mülheim an der Ruhr 45470, Germany; Department of Inorganic Chemistry, Fritz-Haber-Institut der Max-PlanckGesellschaft, Berlin 14195, Germany

Complete contact information is available at: https://pubs.acs.org/10.1021/jacs.1c01655

\section{Funding}

Open access funded by Max Planck Society.

\section{Notes}

The authors declare no competing financial interest.

\section{ACKNOWLEDGMENTS}

The authors acknowledge BESSY II/HZB for allocating beamtime within the project number $16103418 \mathrm{CR}$. This work was supported by the Ministry of Education and Science of the Russian Federation (RFMEFI61614X0007) and the Bundesministerium für Bildung und Forschung (BMBF05K14EWA) through the joint Russian-German research project "SYnchrotron and NEutron STudies for Energy Storage (SYNESTESia). We thank DAAD for financial support in the framework of Taiwanese-German collaboration (projects ID 57218279 and 57392335). C.H.C. acknowledges financial support from projects 104-2112-M-032-005-MY2 and 1052911-I-032-501. S.H. acknowledges funding from EPSRC (EP/K016636/1), and R.W. acknowledges the EPSRC Doctoral Training Award (EP/M506485/1). We thank the High-Performance Computing Center Stuttgart (HLRS) for access to the Hawk supercomputer as part of the ECHO project.

\section{REFERENCES}

(1) Schlögl, R. The role of chemistry in the energy challenge. ChemSusChem 2010, 3, 209-222.

(2) Turner, J. A. Sustainable hydrogen production. Science 2004, 305, 972-974.

(3) Chu, S.; Majumdar, A. Opportunities and challenges for a sustainable energy future. Nature 2012, 488, 294-303.

(4) Walter, M. G.; Warren, E. L.; McKone, J. R.; Boettcher, S. W.; Mi, Q.; Santori, E. A.; Lewis, N. S. Solar water splitting cells. Chem. Rev. 2010, 110, 6446-6473.

(5) Gong, K.; Du, F.; Xia, Z.; Durstock, M.; Dai, L. Nitrogen-doped carbon nanotube arrays with high electrocatalytic activity for oxygen reduction. Science 2009, 323, 760-764.

(6) Gorlin, Y.; Jaramillo, T. F. A bifunctional nonprecious metal catalyst for oxygen reduction and water oxidation. J. Am. Chem. Soc. 2010, 132, 13612.

(7) Lee, Y.; Suntivich, J.; May, K. J.; Perry, E. E.; Shao-Horn, Y. Synthesis and activities of rutile $\mathrm{IrO}_{2}$ and $\mathrm{RuO}_{2}$ nanoparticles for oxygen evolution in acid and alkaline solutions. J. Phys. Chem. Lett. 2012, 3, 399-404.

(8) Wen, T. C.; Hu, C. C. Hydrogen and oxygen evolutions on Ru-Ir binary oxides. J. Electrochem. Soc. 1992, 139, 2158-2163.

(9) Reier, T.; Oezaslan, M.; Strasser, P. Electrocatalytic oxygen evolution reaction (OER) on $\mathrm{Ru}, \mathrm{Ir}$, and Pt catalysts: a comparative 
study of nanoparticles and bulk materials. ACS Catal. 2012, 2, 17651772.

(10) Pfeifer, V.; Jones, T. E.; Velasco Vélez, J. J.; Massué, C.; Arrigo, R.; Teschner, D.; Girgsdies, F.; Scherzer, M.; Greiner, M. T.; Allan, J.; Hashagen, M.; Weinberg, G.; Piccinin, S.; Hävecker; Knop-Gericke, A.; Schlögl, R. The electronic structure of iridium and its oxides. Surf. Interface Anal. 2016, 48, 261-273.

(11) Nong, H. N.; Reier, T.; Oh, H.-S.; Gliech, M.; Paciok, P.; Vu, T. H. T.; Teschner, D.; Heggen, M.; Petkov, V.; Schlögl, R.; Jones, T.; Strasser, P. A unique oxygen ligand environment facilitates water oxidation in hole-doped $\mathrm{IrNiO}_{x}$ core-shell electrocatalysts. Nat. Catal. 2018, 1, 841.

(12) Minguzzi, A.; Lugaresi, O.; Achilli, E.; Locatelli, C.; Vertova, A.; Ghigna, P.; Rondinini, S. Observing the oxidation state turnover in heterogeneous iridium-based water oxidation catalysts. Chem. Sci. 2014, 5, 3591-3597.

(13) Kasian, O.; Grote, J. P.; Geiger, S.; Cherevko, S.; Mayrhofer, K. $\mathrm{J}$. The common intermediates oxygen evolution dissolution reactions during water electrolysis on iridium. Angew. Chem., Int. Ed. 2018, 57, 2488-2491.

(14) Velasco-Vélez, J. J.; Pfeifer, V.; Hävecker, M.; Wang, R.; Centeno, A.; Zurutuza, A.; Algara-Siller, G.; Stotz, E.; Skorupska, K.; Teschner, D.; Kube, P.; Braeuninger-Weimer, P.; Hofmann, S.; Schlögl, R.; Knop-Gericke, A. Atmospheric pressure X-ray photoelectron spectroscopy apparatus: Bridging the pressure gap. Rev. Sci. Instrum. 2016, 87, No. 053121.

(15) Velasco-Vélez, J. J.; Teschner, D.; Girgsdies, F.; Hävecker, M.; Streibel, V.; Willinger, M. G.; Cao, J.; Lamoth, M.; Frei, E.; Wang, R.; Centeno, A.; Zurutuza, A.; Hofmann, S.; Schlögl, R.; Knop-Gericke, A. The Role of Adsorbed and Subsurface Carbon Species for the Selective Alkyne Hydrogenation Over a Pd-Black Catalyst: An Operando Study of Bulk and Surface. Top. Catal. 2018, 61, 20522061.

(16) Velasco-Velez, J. J.; Chuang, C. H.; Han, H.-L.; MartinezFernandez, I.; Martinez, C.; Pong, W.-F.; Shen, Y.-R.; Wang, F.; Zhang, Y.; Guo, J.; Salmeron, M. In-situ XAS investigation of the effect of electrochemical reactions on the structure of graphene in aqueous electrolytes. J. Electrochem. Soc. 2013, 160 (2013), C445C450.

(17) Velasco-Velez, J. J.; Wu, C. H.; Sun; Wang, B. Y.; Sun, Y.; Zhang, Y.; Guo, J.-H.; Salmeron, M. Polarized X-ray Absorption Spectroscopy Observation of Electronic and Structural Changes of Chemical Vapor Deposition Graphene in Contact with Water. J. Phys. Chem. C 2014, 118, 25456-25459.

(18) Tuinstra, F.; Koenig, J. L. Raman spectrum of graphite. J. Chem. Phys. 1970, 53, 1126-1130.

(19) Reich, S.; Thomse, C.; Maultzsch, J. Carbon nanotubes: basics concepts and physical properties; Weinheim: Wiley-VCH Verlag: 2008.

(20) Wang, Y.; Alsmeyer, D. C.; McCreery, R. L. Raman spectroscopy of carbon materials: structural basis of observed spectra. Chem. Mater. 1990, 2, 557-563.

(21) Ismach, A.; Penwell, S.; Schwartzberg, A.; Zheng; Maxwell; Javey, A.; Bokor, J.; Zhang, Y. Direct Chemical Vapor Deposition of Graphene on Dielectric Surfaces. Nano Lett. 2010, 10, 1542-1548.

(22) Velasco-Vélez, J. J.; Jones, T.; Gao, D.; Carbonio, E.; Arrigo, R.; Hsu, C.-J.; Huang, Y.-C.; Dong, C.-L.; Chen, J.-M.; Lee, J.-F.; Strasser, P.; Roldan Cuenya, B.; Schlögl, R.; Knop-Gericke, A.; Chuang, C.-H. The role of the copper oxidation state in the electrocatalytic reduction of $\mathrm{CO}_{2}$ into valuable hydrocarbons. ACS Sustainable Chem. Eng. 2019, $7,1485-1492$.

(23) Knop-Gericke, A.; Pfeifer, V.; Velasco-Vélez, J. J.; Jones, T.; Arrigo, R.; Hävecker, M.; Schlögl, R. In situ X-ray photoelectron spectroscopy of electrochemically active solid-gas and solid-liquid interfaces. J. Electron Spectrosc. Relat. Phenom. 2017, 221, 10-17.

(24) Klyushin, A.; Arrigo, R.; Pfeifer, V.; Jones, T.; Velasco Vélez, J. J. A. Knop-Gericke, Catalyst electronic surface structure under gas and liquid environments. Encyclopedia of Interfacial Chemistry; Elsevier: 2018; pp 615-631.
(25) Velasco-Vélez, J. J.; Falling, L. J.; Bernsmeier, D.; Sear, M. J.; Clark, P. C.; Chan, T. S.; Stotz, E.; Hävecker, M.; Kraehnert, R.; Chuang, C. H.; Starr, D. E.; Favaro, M.; Mom, R. V. A comparative study of electrochemical cells for in situ $\mathrm{x}$-ray spectroscopies in the soft and tender x-ray range. J. Phys. D: Appl. Phys. 2021, 54, 124003.

(26) Giannozzi, P.; Baroni, S.; Bonini, N.; Clandra, M.; Car, R.; Cavazzoni, C.; et al. QUANTUM ESPRESSO: a modular and opensource software project for quantum simulations of materials. J. Phys.: Condens. Matter 2009, 21, 395502.

(27) Dal Corso, A. Pseudopotentials periodic table: From $\mathrm{H}$ to Pu. Comput. Mater. Sci. 2014, 95, 337-350.

(28) Ping, Y.; Galli, G.; Goddard, W. A., III. Electronic structure of $\mathrm{IrO}_{2}$ : the role of the metal d orbitals. J. Phys. Chem. C 2015, 119, $11570-11577$.

(29) Marzari, N.; Vanderbilt, D.; De Vita, A.; Payne, M. C. Thermal contraction and disordering of the Al (110) surface. Phys. Rev. Lett. 1999, 82, 3296-3299.

(30) Shirley, E. L. Ti 1s pre-edge features in rutile: a Bethe-Salpeter calculation. J. Electron Spectrosc. Relat. Phenom. 2004, 136, 77-83.

(31) Vinson, J.; Rehr, J. J.; Kas, J. J.; Shirley, E. L. Bethe-Salpeter equation calculations of core excitation spectra. Phys. Rev. B: Condens. Matter Mater. Phys. 2011, 83, 115106.

(32) Hopfield, J. J. Infrared divergences, X-ray edges, and all that. Comm. Sol. Sta. Phys. 1969, 2, 40-49.

(33) Ouattara, L.; Fierro, S.; Frey, O.; Koudelka, M.; Comninellis, C. Electrochemical comparison of $\mathrm{IrO}_{2}$ prepared by anodic oxidation of pure iridium and $\mathrm{IrO}_{2}$ prepared by thermal decomposition of $\mathrm{H}_{2} \mathrm{IrCl}_{6}$ precursor solution. J. Appl. Electrochem. 2009, 39, 1361-1367.

(34) Gottesfeld, S.; Srinivasan, S. Electrochemical and optical studies of thick oxide layers on iridium and their electrocatalytic activities for the oxygen evolution reaction. J. Electroanal. Chem. Interfacial Electrochem. 1978, 86, 89-104.

(35) Song, S.; Zhang, H.; Ma, X.; Shao, Z.; Baker, R. T.; Yi, B. Electrochemical investigation of electrocatalysts for the oxygen evolution reaction in PEM water electrolyzers. Int. J. Hydrogen Energy 2008, 33, 4955-4961.

(36) Rojas, J. V.; Higgins, M. M.; Gonzalez, M. T.; Castana, C. E. Single step radiolytic synthesis of iridium nanoparticles onto graphene oxide. Appl. Surf. Sci. 2015, 357, 2087-2093.

(37) Frazer, E. J.; Woods, R. The oxygen evolution reaction on cycled iridium electrodes. J. Electroanal. Chem. Interfacial Electrochem. 1979, 102, 127-130.

(38) Velasco-Vélez, J. J.; Jones, T. E.; Streibel, V.; Hävecker, M.; Chuang, C.-H.; Frevel, L.; Plodinec, M.; Centeno, A.; Zurutuza, A.; Wang, R.; Arrigo, R.; Mom, R.; Hofmann, S.; Schlögl, R.; KnopGericke, A. Electrochemically active Ir NPs on graphene for OER in acidic aqueous electrolyte investigated by in situ and ex situ spectroscopies. Surf. Sci. 2019, 681, 1-8.

(39) Frevel, L. J.; Mom, R.; Velasco-Vélez, J. J.; Plodinec, M.; KnopGericke, A.; Schlögl, R.; Jones, T. E. In Situ X-ray Spectroscopy on the Electrochemical Development of Iridium Nanoparticles in Confined Electrolyte. J. Phys. Chem. C 2020, 124, 14941-14943.

(40) Pfeifer, V.; Jones, T. E.; Velasco Vélez, J. J.; Arrigo, R.; Piccinin, S.; Hävecker, M.; Knop-Gericke, A.; Schlögl, R. In situ observation of reactive oxygen species forming on oxygen-evolving iridium surfaces. Chem. Sci. 2017, 8, 2143-2149.

(41) Willinger, E.; Massué, C.; Schlögl, R. Identifying key structural features of $\mathrm{IrO}_{\mathrm{x}}$ water splitting catalysts. J. Am. Chem. Soc. 2017, 139, 12093-12101.

(42) Massué, C.; Pfeifer, V.; Huang, X.; Noack, J.; Tarasov, A.; Cap, S.; Schlögl, R. High-performance supported iridium oxohydroxide water oxidation electrocatalysts. ChemSusChem 2017, 10, 1943-1957.

(43) Kolmakov, A.; Dikin, D. A.; Cote, L. J.; Huang, J.; Abyaneh, M. K.; Amati, M.; Gregoratti, L.; Günther, S.; Kiskinova, M. Graphene oxide windows for in situ environmental cell photoelectron spectroscopy. Nat. Nanotechnol. 2011, 6, 651-657.

(44) Velasco-Vélez, J. J.; Pfeifer, V.; Hävecker, M.; Weatherup, R. S.; Arrigo, R.; Chuang, C.-H.; Stotz, E.; Weinberg, G.; Salmeron, M.; Schlögl, R.; Knop-Gericke, A. Photoelectron Spectroscopy at the 
Graphene-Liquid Interface Reveals the Electronic Structure of an Electrodeposited Cobalt/Graphene Electrocatalyst. Angew. Chem., Int. Ed. 2015, 54, 14554-14558.

(45) Velasco-Vélez, J. J.; Wu, C. H.; Pascal, T.; Wan, L. F.; Guo, J.; Prendergast, D.; Salmeron, M.; et al. The structure of interfacial water on gold electrodes studied by $\mathrm{x}$-ray absorption spectroscopy. Science 2014, 346, 831-834.

(46) Itkis, D. M.; Velasco Vélez, J. J.; Knop-Gericke, A.; Vyalikh, A.; Avdeev, M. V.; Yashina, L. V. Probing operating electrochemical interfaces by photons and neutrons. ChemElectroChem 2015, 2, 1427-1445.

(47) Carbonio, E. A.; Velasco-Velez, J. J.; Schlögl, R.; Knop-Gericke, A. Perspective-outlook on operando photoelectron and absorption spectroscopy to probe catalysts at the solid-liquid electrochemical Interface. J. Electrochem. Soc. 2020, 167, 054509.

(48) Clancy, J. P.; Chen, N.; Kim, C. Y.; Chen, W. F.; Plumb, K. W.; Jeon, B. C.; Noh, T. W.; Kim, Y. J. Spin-orbit coupling in iridiumbased $5 \mathrm{~d}$ compounds probed by x-ray absorption spectroscopy. Phys. Rev. B: Condens. Matter Mater. Phys. 2012, 86, 195131.

(49) Jo, T. X-ray magnetic circular dichroism, symmetry and orbital magnetization. J. Phys. Soc. Jpn. 1993, 62 (1993), 1814-1815.

(50) Dehmer, J. L.; Starace, A. F. Potential-Barrier Effects in Photoabsorption. III. Application to 4 d-Shell Photoabsorption in Lanthanum. Phys. Rev. B 1972, 5, 1792-1796.

(51) Hüppauff, M.; Lengeler, B. Valency and structure of iridium in anodic iridium oxide films. J. Electrochem. Soc. 1993, 140, 598-602.

(52) Mo, Y.; Stefan, I. C.; Cai, W. B.; Dong, J.; Caey, P.; Scherson, D. A. In situ iridium $\mathrm{L}_{\mathrm{III}}$-edge $\mathrm{X}$-ray absorption and surface enhanced Raman spectroscopy of electrodeposited iridium oxide films in aqueous electrolytes. J. Phys. Chem. B 2002, 106, 3681-3686.

(53) Minguzzi, A.; Locatelli, C.; Lgaresti, O.; Achilli, E.; Cappalletti, G.; Scavini, M.; Coduri, M.; Masala, P.; Sacchi, B.; Vertova, A.; Ghigna, P.; Rondinini, S. Easy accommodation of different oxidation states of iridium oxide nanoparticles with different hydration degree as water oxidation electrocatalysts. ACS Catal. 2015, 5, 5104-5115.

(54) Pfeifer, V.; Jones, T. E.; Wrabetz, S.; Massué, C.; Velasco Vélez, J. J.; Arrigo, R.; Scherzer, M.; Piccinin, S.; Hävecker, M.; KnopGericke, A.; Schlögl, R. Reactive oxygen species in iridium-based OER catalysts. Chem. Sci. 2016, 7, 6791-6795.

(55) Li, L.; Yang, J.; Ali-Löytty, H.; Weng, T. C.; Toma, F. M.; Sokaras, D.; Sharp, I. D.; Nilsson, A. Operando observation of chemical transformations of iridium oxide during photoelectrochemical water oxidation. ACS Appl. En. Mater. 2019, 2, 1371-1379.

(56) Seitz, L. C.; Dickens, C. F.; Nishio, K.; Hikita, Y.; Montoya, J.; Doyle, A.; Kirk, C.; Vojvodic, A.; Hwang, H.; Norskov, J.; Jaramillo, T. F. A highly active and stable $\mathrm{IrOx} / \mathrm{SrIrO} 3$ catalyst for the oxygen evolution reaction. Science 2016, 353 (6303), 1011-1014.

(57) Wan, G.; Freeland, J. W.; Kloppenburg, J.; Petretto, G.; Nelson, J. N.; Kuo, D.; et al. Amorphization mechanism of $\mathrm{SrIrO}_{3}$ electrocatalyst: How oxygen redox initiates ionic diffusion and structural reorganization. Sci. Adv. 2021, 7 (2), eabc7323.

(58) Birss, V.; Myers, R.; Angerstein-Kozlowska, H.; Conway, B. E. Electron microscopy study of formation of thick oxide films on Ir and Ru electrodes. J. Electrochem. Soc. 1984, 131, 1502-1510.

(59) Augustynski, J.; Koudelka, M.; Sanchez, J.; Conway, B. E. ESCA study of the state of iridium and oxygen in electrochemically and thermally formed iridium oxide films. J. Electroanal. Chem. Interfacial Electrochem. 1984, 160, 233-248.

(60) Opalka, D.; Scheurer, C.; Reuter, K. Ab Initio Thermodynamics Insight into the Structural Evolution of Working $\mathrm{IrO}_{2}$ Catalysts in Proton-Exchange Membrane Electrolyzers. ACS Catal. 2019, 9, 4944-4950.

(61) Abbott, D. F.; Lebedev, D.; Waltar, K.; Povia, M.; Nachtegaal, M.; Fabbri, E.; Copéret, C.; Schmidt, T. J. Iridium oxide for the oxygen evolution reaction: correlation between particle size, morphology, and the surface hydroxo layer from operando XAS. Chem. Mater. 2016, 28, 6591-6604.

(62) Weber, D.; Schoop, L. M.; Wurmbrand, D.; Nuss, J.; Seibel, E. M.; Tafti, F. F.; Ji, H.; Cava, R. J.; Dinnebier, R. E.; Lotsch, B. V.
Trivalent iridium oxides: layered triangular lattice iridate $\mathrm{K}_{0.75} \mathrm{Na}_{0.25} \mathrm{IrO}_{2}$ and oxyhydroxide IrOOH. Chem. Mater. 2017, 29, $8338-8345$.

(63) Pfeifer, V.; Jones, T. E.; Velasco Vélez, J. J.; Massué, C.; Greiner, M. T.; Arrigo, R.; Teschner, D.; Girgsdies, F.; Scherzer, M.; Allan, J.; Hashagen, M.; Weinberg, G.; Piccinin, S.; Hävecker, M.; Knop-Gericke, A.; Schlögl, R. The electronic structure of iridium oxide electrodes active in water splitting. Phys. Chem. Chem. Phys. 2016, 18, 2292-2296.

(64) Shirley, D. A. High-resolution X-ray photoemission spectrum of the valence bands of gold. Phys. Rev. B 1972, 5, 4709.

(65) Kötz, R.; Neff, H.; Stucki, S. Anodic Iridium Oxide Films XPSStudies of Oxidation State Changes and. J. Electrochem. Soc. 1984, 131 (1984), 72-77.

(66) Sanchez Casalongue, H. G.; Ng, M. L.; Kaya, S.; Friebel, D.; Ogasawara, H.; Nilsson, A. In situ observation of surface species on iridium oxide nanoparticles during the oxygen evolution reaction. Angew. Chem., Int. Ed. 2014, 53, 7169-7172.

(67) Sachse, R.; Pflüger, M.; Velasco-Vélez, J. J.; Sahre, M.; Radnik, J.; Bernicke, M.; Bernsmeier; Hodoroaba, V.-D.; Krumrey, M.; Strasser, P.; Kraehnert, R.; Hertwig, A. Assesing optical and electrical properties of highlgy active catalysts for the electrochemical oxygen evolution reacation via spectroscopic ellipsometry. ACS Catal. 2020, $10,14210-14223$.

(68) Mom, R.; Frevel, L.; Velasco-Vélez, J. J.; Plodinec, M.; KnopGericke, A.; Schlögl, R. The oxidation of platinum under wet conditions observed by electrochemical X-ray photoelectron spectroscopy. J. Am. Chem. Soc. 2019, 141, 6537-6544.

(69) Velasco-Velez, J. J.; Mom, R. V.; Sandoval-Diaz, L. E.; Falling, L. J.; Chuang, C. H.; Gao, D.; et al. Revealing the active phase of copper during the electroreduction of $\mathrm{CO}_{2}$ in aqueous electrolyte by correlating in situ X-ray spectroscopy and in situ electron microscopy. ACS energy letters 2020, 5, 2106-2111.

(70) Falling, L. J.; Mom, R. V.; Sandoval Diaz, L. E.; Nakhaie, S.; Stotz, E.; Ivanov, D.; et al. Graphene-capped liquid thin films for electrochemical operando X-ray spectroscopy and scanning electron microscopy. ACS Appl. Mater. Interfaces 2020, 12, 37680-37692.

(71) Saveleva, V. A.; Wang, L.; Teschner, D.; Jones, T.; Gago, A. S.; Friedrich, K. A.; Zafeiratos, S.; Schlögl, R.; Savinova, E. R. Operando evidence for a universal oxygen evolution mechanism on thermal and electrochemical iridium oxides. J. Phys. Chem. Lett. 2018, 9, 31543160.

(72) Ping, Y.; Nielsen, R. J.; Goddard, W. A., III The reaction mechanism with free energy barriers at constant potentials for the oxygen evolution reaction at the $\mathrm{IrO}_{2}$ (110) surface. J. Am. Chem. Soc. 2017, 139, 149-155.

(73) Nong, H. N.; Falling, L. J.; Bergmann, A.; Klingenhof, M.; Tran, H. P.; Spöri, C. Key role of chemistry versus bias in electrocatalytic oxygen evolution. Nature 2020, 587, 408-413. 